AIAA 2001-3439

\title{
THERMAL CHARACTERIZATION OF EPOXY ADHESIVE BY HOTFIRE TESTING
}

\author{
Ken A. Spomer and M. Reed Haddock \\ Thiokol Propulsion, a Division of Cordant Technologies Inc. \\ P.O. Box 707 \\ Brigham, Utah 84302-0707
}

\begin{abstract}
This paper describes subscale solid-rocket motor hotfire testing of epoxy adhesives in flame surface bondlines to evaluate heat-affected depth, char depth and ablation rate. Hot-fire testing is part of an adhesive down-selection program on the Space Shuttle Solid Rocket Motor Nozzle to provide additional confidence in the down-selected adhesives. The current nozzle structural adhesive bond system is being replaced due to obsolescence. Prior to hot-fire testing, adhesives were tested for chemical, physical and mechanical properties, which resulted in the selection of two potential replacement adhesives, Resin Technology Group's TIGA 321 and 3M's EC2615XLW. Hot-fire testing consisted of four forty-pound charge (FPC) motors fabricated in configurations that would allow side-by-side comparison testing of the candidate replacement adhesives with the current RSRM adhesives. Results of the FPC motor testing show that 1) The phenolic char depths on radial bondlines is approximately the same and vary depending on the position in the blast tube regardless of which adhesive was used, 2) The replacement candidate adhesive char depths are equivalent to the char depths of the current adhesives, 3) The heat-affected depths of the candidate and current adhesives are equivalent, 4) The ablation rates for both replacement adhesives were equivalent to the current adhesives.
\end{abstract}

\section{Introduction}

The Space Shuttle Reusable Solid Rocket Motor (RSRM) uses epoxy adhesives to bond phenolic insulation liners to metal housings and in radial bondlines between phenolic rings. The phenolic linerto- metal housing bonds are structural and as such are adequately isolated from the flameside environment

Copyright (C) 2001 by Thiokol Propulsion, a division of Cordant Technologies, Inc. Published by the American Institute of Aeronautics and Astronautics, Inc. with permission. by the liners thickness. The liner-to-liner bonds or radial bonds occur where separate liner "rings" butt against each other as they are bonded to the metal housing. The purpose of the adhesive in the resulting liner-to-liner radial bondlines, which intersect the flame surface, is primarily to fill the radial bond gaps and prevent hot gas penetration to the structural bondlines.

The current nozzle structural adhesive bond system is being replaced due to obsolescence. Replacing the RSRM nozzle structural adhesive requires that all aspects of adhesive testing be performed and the replacement adhesive be fully characterized. The intent of this testing was to obtain thermal performance characteristics of the proposed replacement and current baseline nozzle adhesives in narrow gaps at and near the nozzle flame surface.

The testing was conducted using Forty Pound Charge (FPC) motors with both current and candidate adhesives in flame surface radial bondlines. The FPC configuration was designed primarily as a test bed for performance testing of nozzle ablative phenolic materials, but was adapted for this adhesive bondline evaluation. Hot-fire testing was used to obtain surface char and erosion behavior comparisons that were used to assist in the final selection of the primary replacement adhesive.

Testing evaluated two candidate replacement adhesives and two current adhesives. Dexter Hysol EA-913NA and EA-946 are the current RSRM adhesives. The replacement candidate adhesives are Minnesota Mining and Manufacturing's (3M) EC2615XLW and Resin Technology Group's (RTGs) TIGA 321.

\section{$\underline{\text { Test }}$}

Adhesive thermal performance testing was conducted using four forty-pound charge motors. The FPC 
Adhesive thermal performance testing was conducted using four forty-pound charge motors. The FPC consists of a propellant case and nozzle. The nozzle consists of a housing, convergent cone, blast tube, throat and exit cone (See Figure 1).

The FPC configuration was designed primarily as a test bed for performance testing of nozzle ablative materials. For this test the blast tube section of the nozzle was changed to have five Carbon Cloth Phenolic (CCP) test rings instead of the usual two. This resulted in three additional radial bondlines (total of four) "sandwiched" between Carbon Cloth Phenolic
(CCP) test rings. The blast tube was cut longitudinally such that the radial bondlines in one 180-degree half (pack) used current RSRM adhesives, while those of the other half (pack) used the proposed adhesives.

Each replacement candidate adhesive was tested eight times, two times each at four locations. This configuration was designed so that each candidate adhesive could be compared to each current adhesive at each station in the blast tube (see Table 1 and Figure 2 ). The noted configuration was prepared assuming that the same axial station in the nozzle would have the same flow velocities, pressures and temperature.

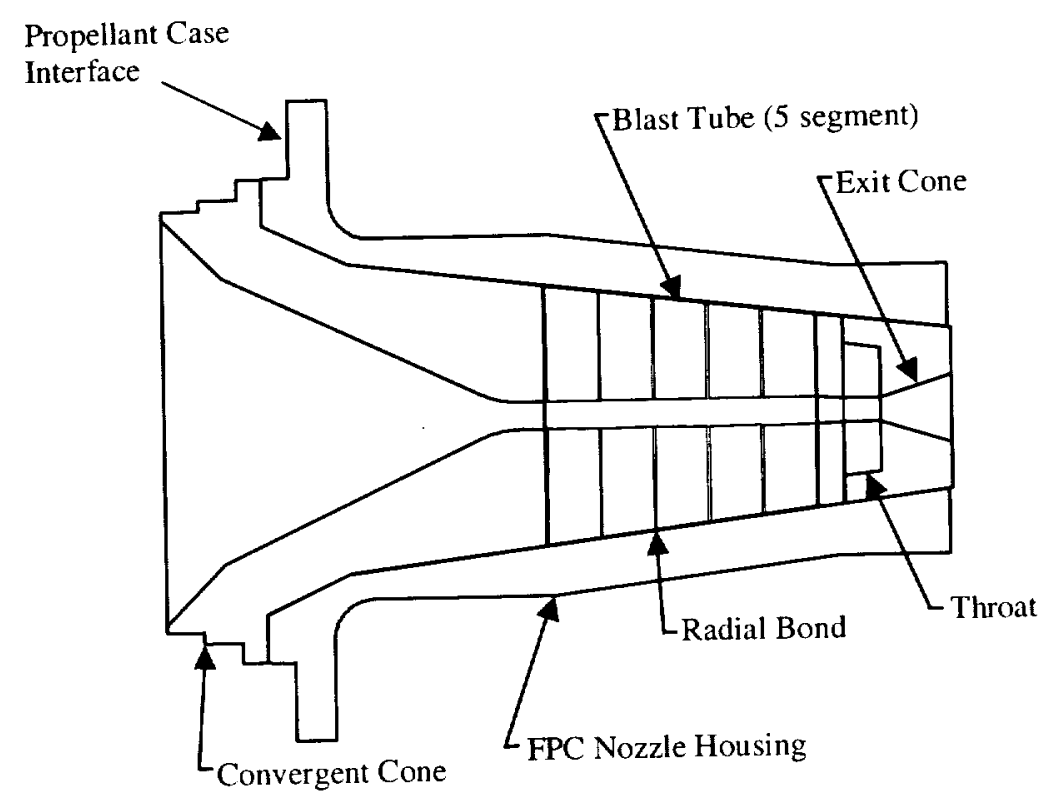

Figure 1: FPC Nozzle

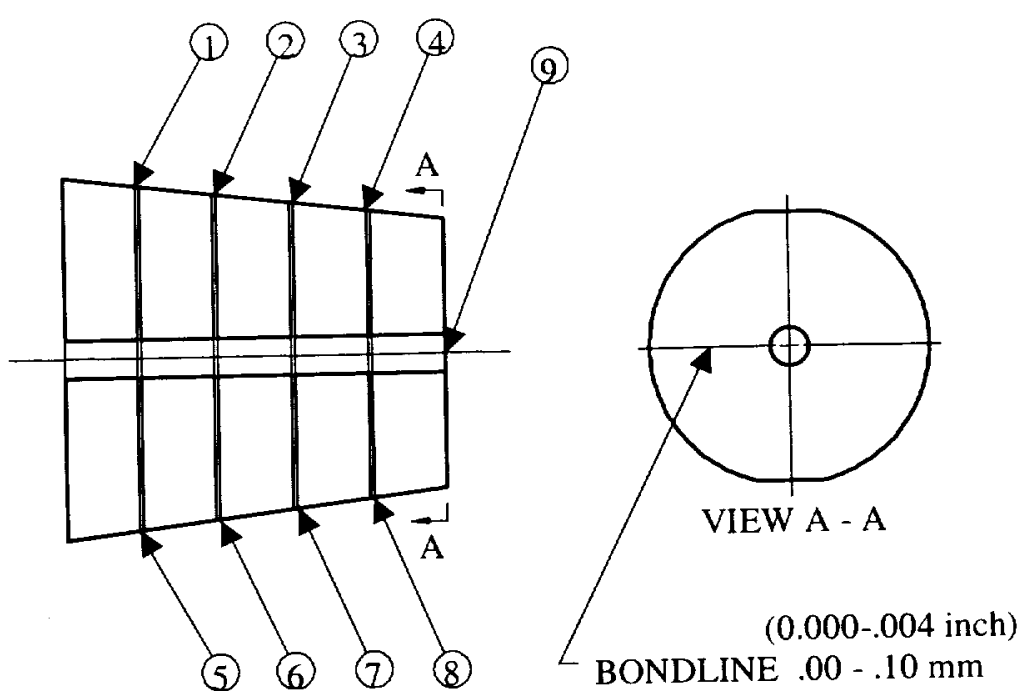


Figure 2: FPC Blast Tube Configuration

Table 1: FPC Char Motor Adhesive Layout

\begin{tabular}{|c|c|c|c|c|c|c|c|c|c|}
\hline Test & \multicolumn{9}{|c|}{ Bond Location } \\
\hline & 1 & 2 & 3 & 4 & 5 & 6 & 7 & 8 & 9 \\
\hline 1 & EA-913 & EA-913 & EA-913 & EA-913 & $3 \mathrm{M}$ & $3 \mathrm{M}$ & RTG & RTG & EA-913 \\
\hline 2 & EA-946 & EA-946 & EA-946 & EA-946 & $3 \mathrm{M}$ & $3 \mathrm{M}$ & RTG & RTG & EA-913 \\
\hline 3 & EA-913 & EA-913 & EA-913 & EA-913 & RTG & RTG & $3 \mathrm{M}$ & $3 \mathrm{M}$ & EA-913 \\
\hline 4 & EA-946 & EA-946 & EA-946 & EA-946 & RTG & RTG & $3 \mathrm{M}$ & $3 \mathrm{M}$ & EA-913 \\
\hline
\end{tabular}

All radial bondlines were approximately $1.0 \mathrm{~mm}(.040$ inch) thick with the axial bondline being $.001-.100 \mathrm{~mm}$ (.000 - .004 inch). Thermocouples were placed in the radial bondlines starting $2.54 \mathrm{~mm}(.100$ inch) in from the flame surface and every $5.08 \mathrm{~mm}(.200 \mathrm{inch})$ increment out toward the housing bond surface (see Figure 3).
The thermocouples were intended to provide information on thermal gradients through the bondlines for current and replacement candidate adhesives. Placement of the thermocouples was such that two in each bondline would be destroyed during testing to obtain an ablation rate and two would remain through heat soak. Key FPC char motor operating parameters are as follows:
Propellant

Motor Burn Time

Test Orientation

Average Pressure
Shuttle

$32 \pm 2$ seconds

Vertical

$4.826 \pm .345 \mathrm{MPa}(700 \pm 50 \mathrm{psi})$

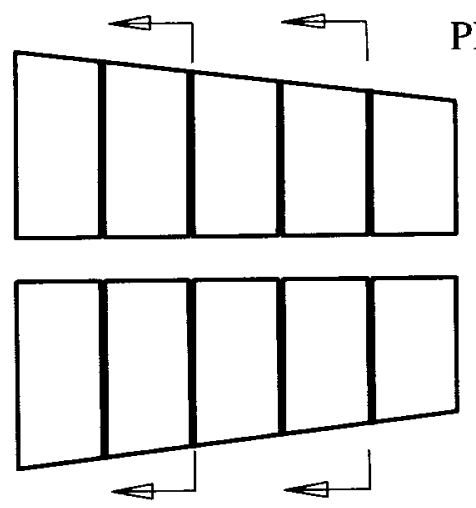

PRED. EROSION

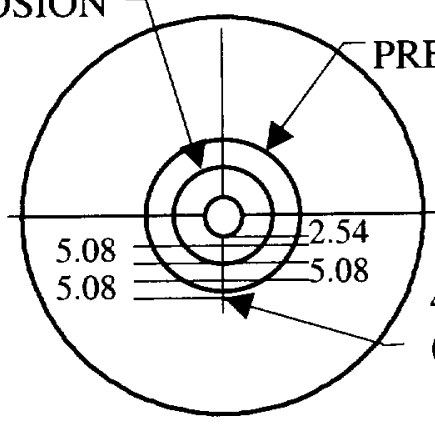

$4 \times$ TC LOC

(2 PLACES)

\section{CROSS SECTION VIEW (TYPICAL)}

Dimensions in $\mathrm{mm}$ 


\section{Figure 3: FPC Blast Tube Thermocouple Configuration \\ Experimental and Analytical Procedures}

To build the test motor that would allow a side-by-side comparison test, a unique blast tube had to be manufactured. To start with, five conical blast tube phenolics approximately $25 \mathrm{~mm}$ ( 1 inch) thick were built. The phenolics were stacked and aligned using a $12.7 \mathrm{~mm}$ (.5 inch) diameter alignment tool placed inside the blast tube. Two flat areas were machined on the phenolic outside diameters, the length of the blast tube. They were aligned $180^{\circ}$ apart to provide a wiring path for instrumentation on each side of the blast tube. The individual phenolics were then sectioned into $180^{\circ}$ halves. The appropriate section halves were instrumented with thermocouples and bonded per Table 1 and Figure 2 . A $12.7 \mathrm{~mm}$ (.5 inch) diameter alignment rod was used to align the center bores of the blast-tube sections while the assembly was being assembled and clamped together. This procedure produced a $180^{\circ}$ pack. Two bonded packs were then bonded to form the blast tube assembly.
Before the motors were fired, the bondlines were inspected and prefire measurements were taken. At the testing facility, the propellant case was mounted into the test fixture in the vertical position. The nozzle assembly was assembled to the propellant case, the instrumentation connected and functioning, and the FPCs fired. After cooling, the assemblies were removed, disassembled and inspected.

\section{$\underline{\text { Results }}$}

Photographs were taken of the disassembled phenolic sections and radial bondlines (see figure 4).

Measurements of adhesive char and heat-affected depth in the bondlines were recorded (see Table 2, Figure 5). The averages of the four post-fire FPC char and heataffected depth measurements, for each adhesive, are shown in Table 2 .

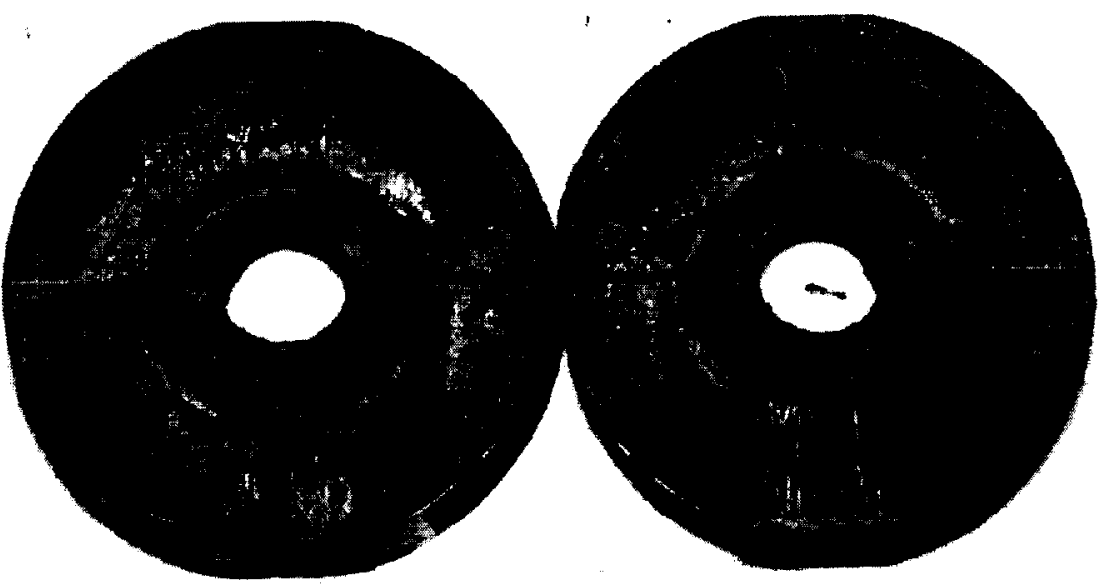

Figure 4: Typical Post Fire Bondline

Table 2: Post Fire Measurement

\begin{tabular}{|l|c|c|c|}
\hline Adhesive & $\begin{array}{c}\text { Pre-Fire Blast } \\
\text { Tube Dia. } \mathrm{mm} /(\mathrm{in})\end{array}$ & $\begin{array}{c}\text { Char Depth Adhesive } \\
\text { (Avg Dia) } \mathrm{mm} /(\mathrm{in})\end{array}$ & $\begin{array}{c}\text { Heat Affected Adhesive } \\
\text { (Avg. Dia) mm/(in) }\end{array}$ \\
\hline EA913NA & $12.7 /(.5)$ & $51 /(2.01)$ & $56 /(2.21)$ \\
\hline EA946 & $12.7 /(.5)$ & $52 /(2.05)$ & $57 /(2.24)$ \\
\hline TIGA 321 & $12.7 /(.5)$ & $48.5 /(1.91)$ & $51.5 /(2.01)$ \\
\hline EC2615XLW & $12.7 /(.5)$ & $49.5 /(1.95)$ & $53 /(2.09)$ \\
\hline
\end{tabular}




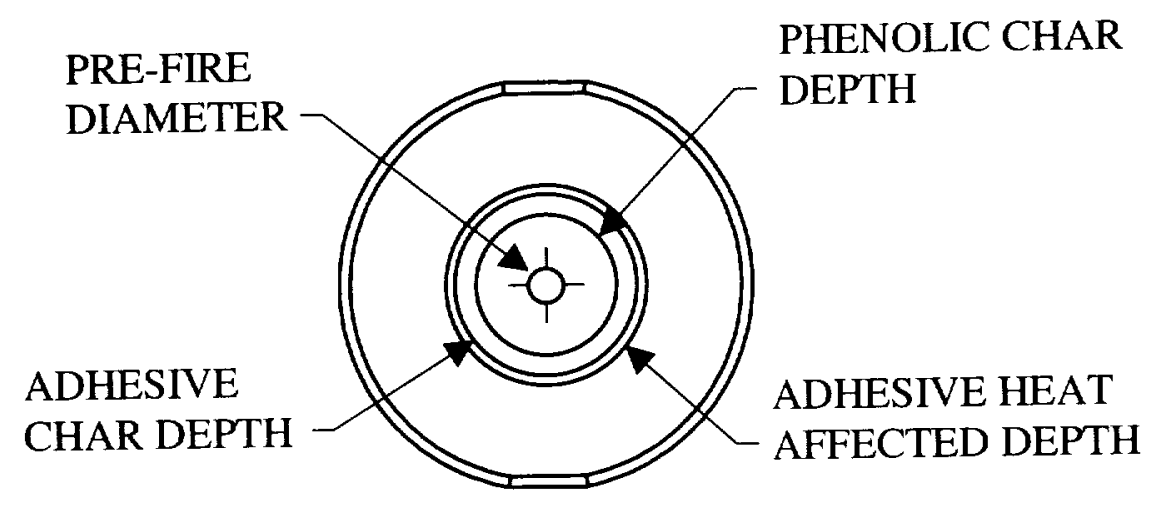

Figure 5: Typical Cross Section View

The intent of the thermocouples was to identify how fast the ablation of the adhesive occurred. The pressure transducers were used to plot the chamber pressure during the test (See Figures 6-10). This data was used to identify the temperature and pressure during the ablation and to calculate an ablation rate. What the thermocouple data shows is that the first $2-5 \mathrm{~mm}(.100$ .200 inch) of adhesive ablate very quickly (on the order of 1 second) and in advance of the surrounding phenolic material. Following this initial adhesive ablation, the ablation rate slows and seems to follow the char and decomposition zone that advances at a relatively uniform rate through the phenolic. The first thermocouples lost meaningful signal on the average of 1 second into the burn at an average pressure of $8.27 \mathrm{MPa}$ (1200 psi). The second thermocouple in from the flame surface lost meaningful signal at an average of 15 seconds after ignition and 5.5 MPa (800 psi) pressure. The adhesive ablation rate was calculated using the distance from the original flame surface to the second thermocouple divided by the time to reach the thermocouple-operating limit (See Table 3).

No anomalies were reported during the build, test or post fire inspection.

Table 3: Calculated Adhesive Ablation Rate

\begin{tabular}{|l|c|}
\hline Adhesive & $\begin{array}{c}\text { Average Ablation Rate } \\
\mathrm{mm} / \mathrm{sec} /(\mathrm{in} / \mathrm{sec})\end{array}$ \\
\hline EA-946 & $.53 /(.021)$ \\
\hline EA-913 & $.59 /(.023)$ \\
\hline TIGA 321 & $.51 /(.020)$ \\
\hline EC-2615XLW & $.52 /(.021)$ \\
\hline
\end{tabular}




\section{Conclusions}

There are four conclusions that can be drawn from this testing. 1) The phenolic char depths of the radial bondlines are approximately the same and vary depending on the position in the blast tube regardless of which adhesive was used. 2) The adhesive char depths of the candidate replacement adhesives are equivalent to the char depths of the current adhesives. 3) The heat-affected depths of the candidate replacement adhesives are equivalent to the heat-affected depth of the current adhesives. 4) The ablation rates for both replacement adhesives are equivalent or lower than the current adhesives.
The results of this testing suggest that epoxies, in general, ablate about the same in radial bondlines between phenolics exposed to the flame front. Based on the temperatures measured, it is believed that the motor flameside thermal environment quickly decomposes the surface adhesive (all adhesives tested) to a depth below the surrounding phenolic flame surface. Once the narrow gap adhesive is sufficiently "ablated" or recessed below the surface and effectively isolated from the direct flameside environment, further decomposition or char appears to track the char penetration of the surrounding phenolic. All adhesives tested, tracked the phenolic char penetration equivalently.

FPC Motor Test

ETP-1541-001

Pooz Chamber Pressure.

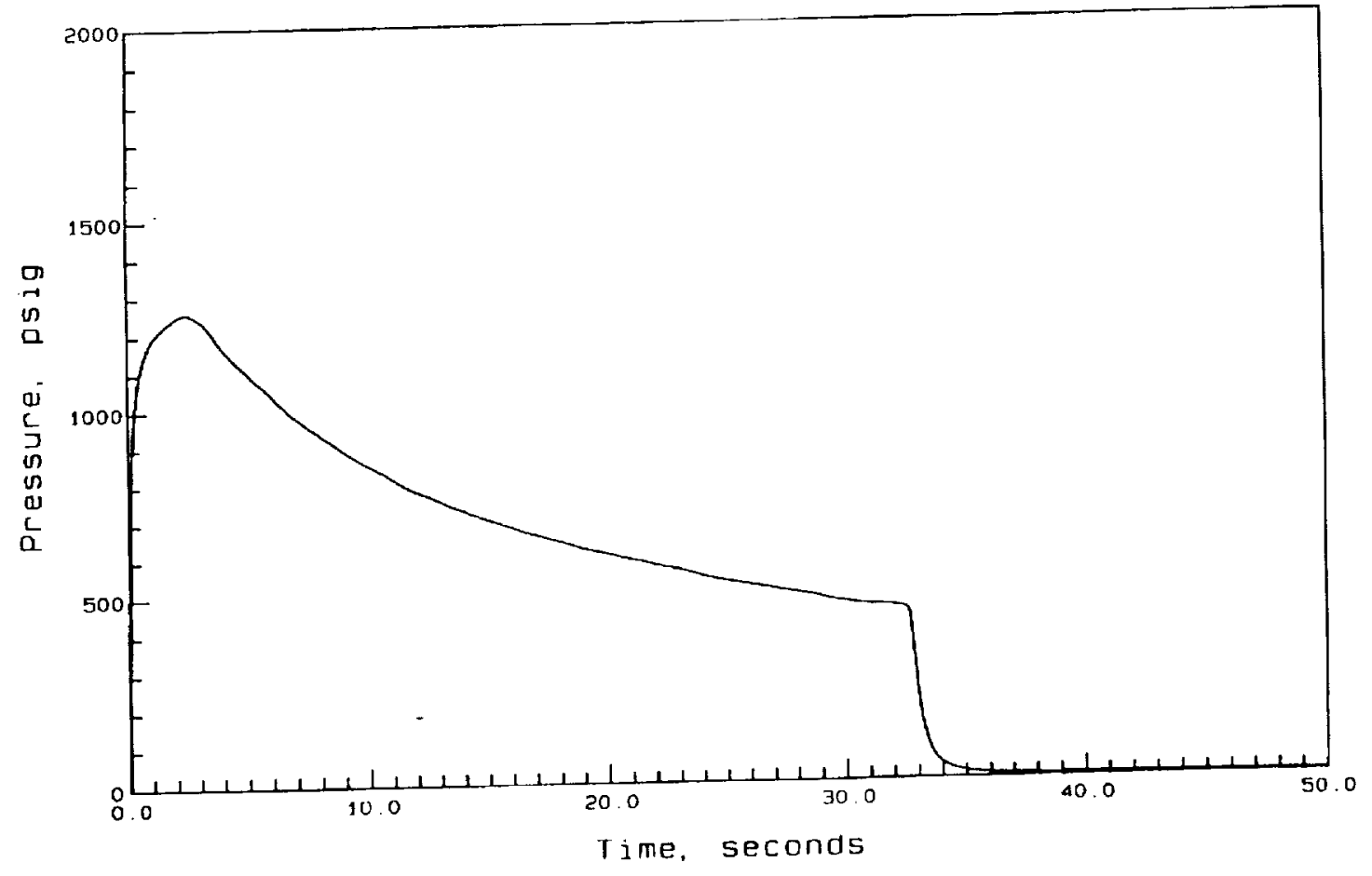

Figure 6: Typical Chamber Pressure Plot 
FPC Motor Test

ETP-1541-001

TC13.

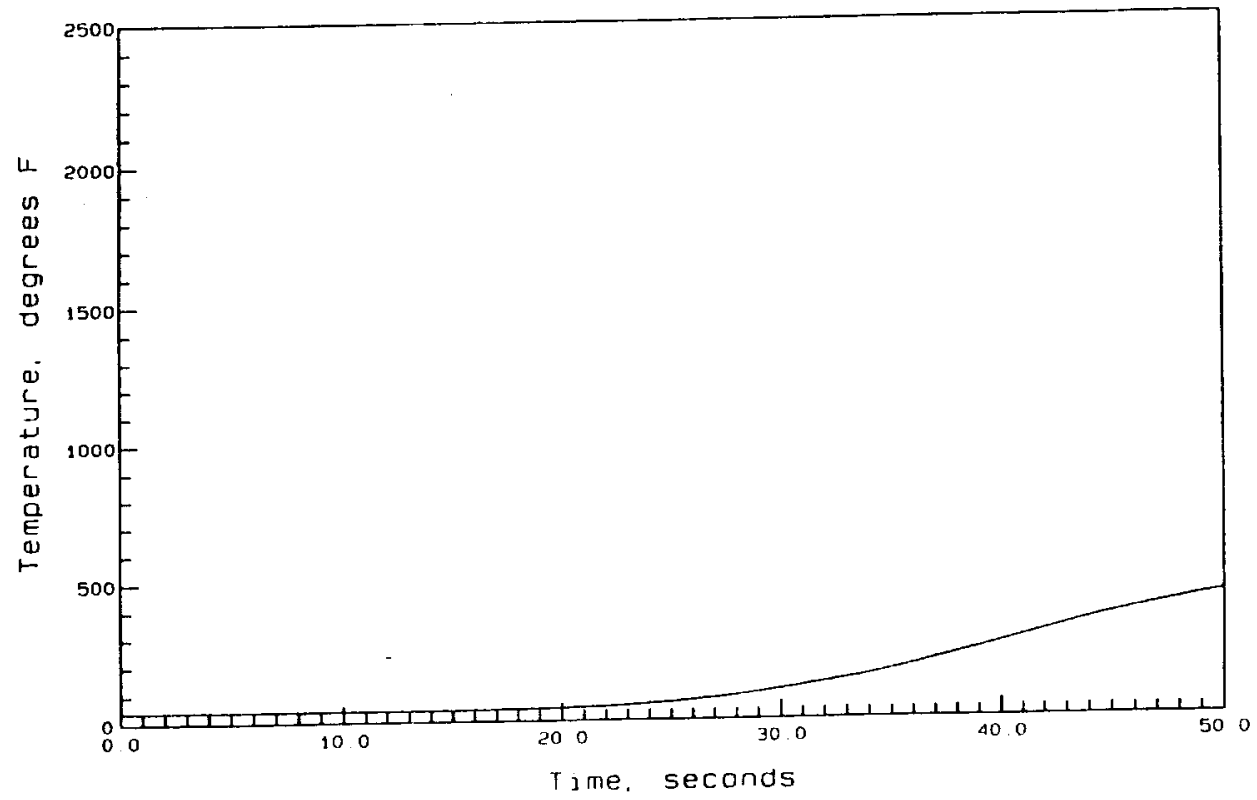

Figure 7: Typical Outer Thermocouple Plot

FPC Mator Test

ETP-1541-001

TC14.

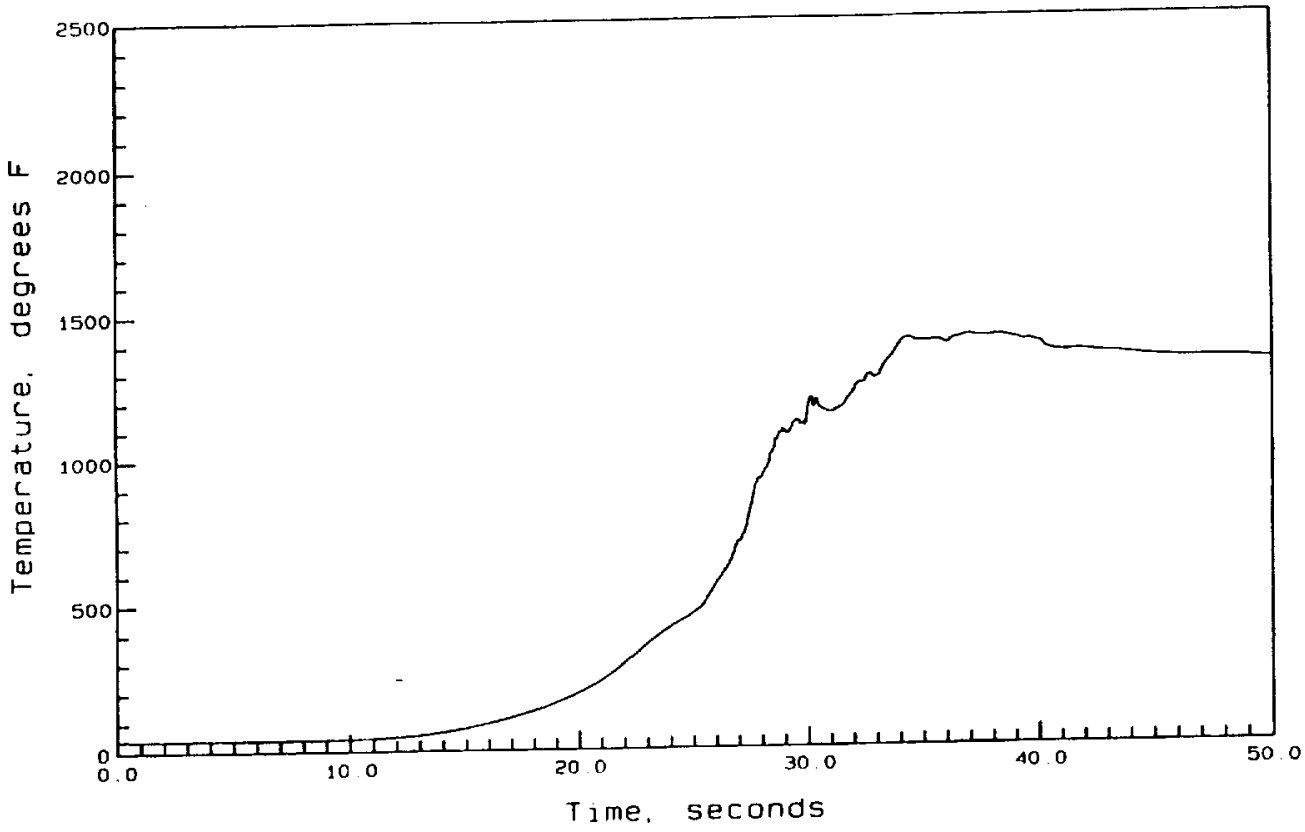

Figure 8: Typical Middle Outer Thermocouple Plot 


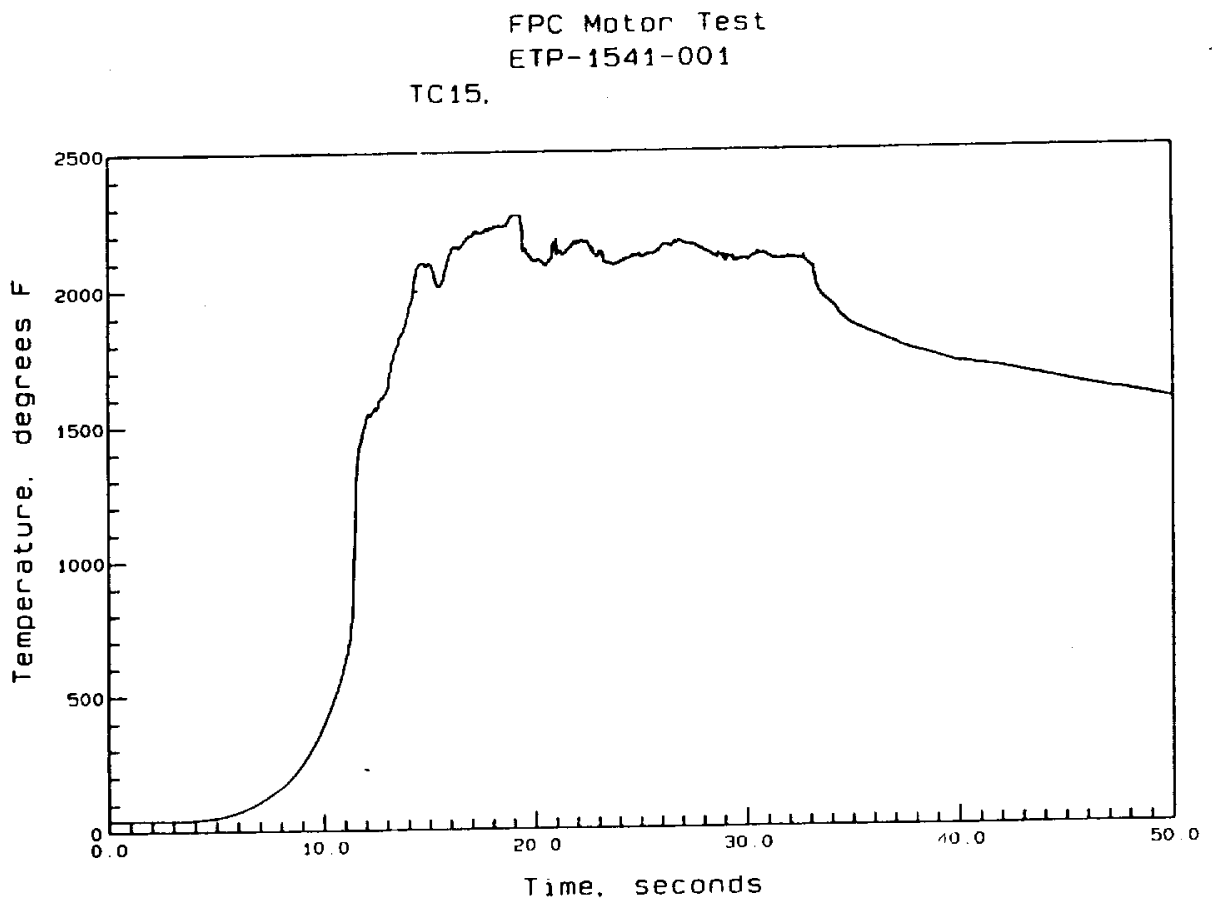

Figure 9: Typical Middle Inner Thermocouple Plot

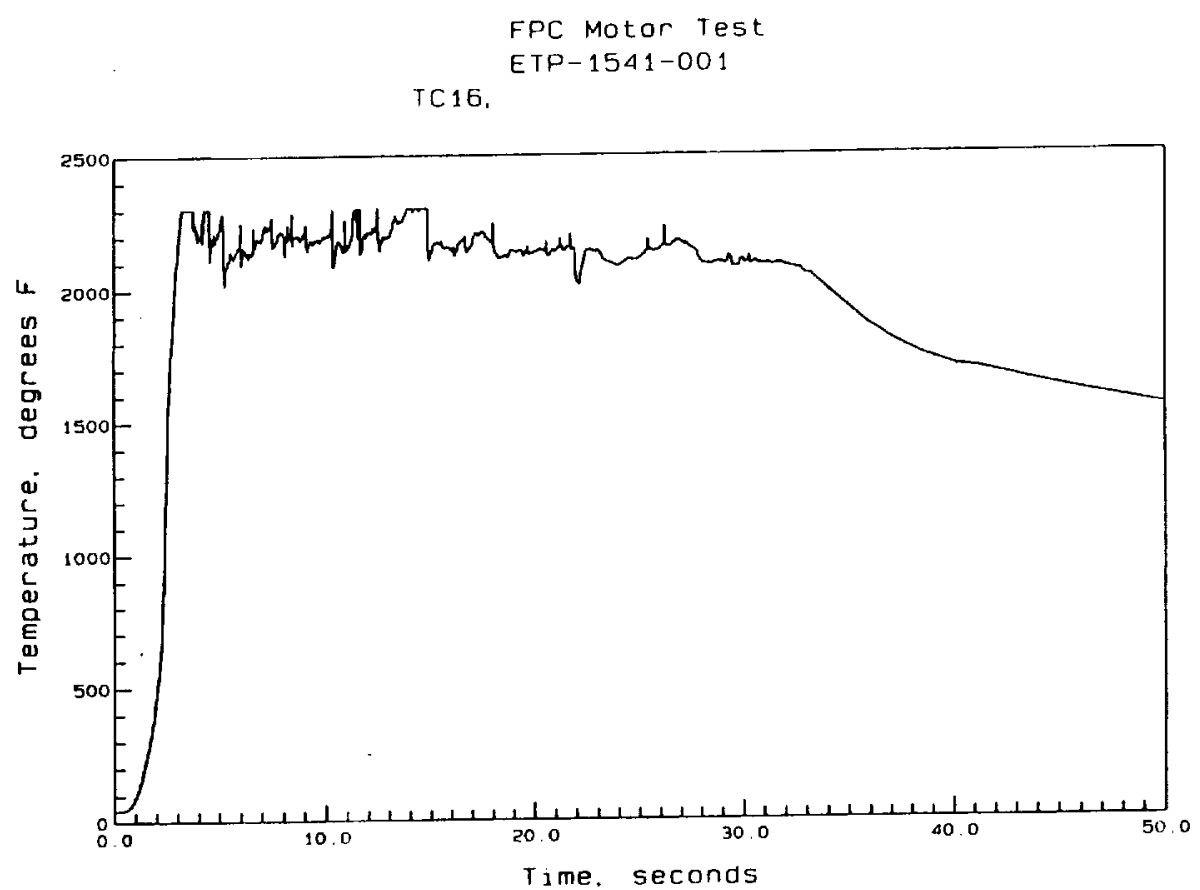

Figure 10: Typical Inner. Thermocouple Plot 